\title{
The novel herbal cocktail MA128 suppresses tumor growth and the metastatic potential of highly malignant tumor cells
}

\author{
AEYUNG KIM, MINJU IM, NAM-HIU YIM, YOUN-HWAN HWANG, \\ HYE JIN YANG and JIN YEUL MA
}

\begin{abstract}
Korean Medicine (KM)-Based Herbal Drug Development Group, Korea Institute of Oriental Medicine (KIOM), Daejeon 305-811, Republic of Korea
\end{abstract}

Received March 17, 2015; Accepted April 29, 2015

DOI: $10.3892 /$ or.2015.4018

\begin{abstract}
MA128, a novel herbal medicine, was previously identified and its effectiveness in the treatment of asthma and atopic dermatitis (AD) was demonstrated. In particular, post-inflammatory hyperpigmentation $(\mathrm{PIH})$ in AD mice was improved by treatment with MA128. In addition, MA128 exhibited anti-melanogenic activity by inhibiting tyrosinase activity via the p38 MAPK and protein kinase A signaling pathways in B16F10 cells. In the present study, we examined whether oral administration of MA128 suppressed the in vivo tumor growth of HT1080 cells in athymic nude mice. The results showed that the daily oral administration of 75 and $150 \mathrm{mg} / \mathrm{kg}$ MA128 suppressed the tumorigenic growth of HT1080 cells efficiently. Since metastasis is a major cause of cancer-associated mortality and the greatest challenge during cancer treatment, we investigated the effect of non-toxic concentrations of MA128 on the metastatic potential of HT1080 cells. MA128 inhibited anchorageindependent colony formation, migration and invasion. Matrix metalloproteinase-9 (MMP-9) activity under resting and PMA-stimulated conditions was decreased in a dosedependent manner by MA128 in HT1080 cells. In addition, the daily oral administration of MA128 at doses of 75 and $150 \mathrm{mg} / \mathrm{kg}$ efficiently blocked the lung metastasis of B16F10 cells that had been injected into the tail veins of C57BL/6 mice. In particular, none of the mice treated with MA128 exhibited systemic toxicity, such as body weight loss or liver and kidney dysfunction. MA128 also inhibited tumor-induced angiogenesis. Taken together, the results suggest that MA128 is a potential therapeutic agent and a safe herbal medicine for controlling malignant and metastatic cancer.
\end{abstract}

Correspondence to: Dr Jin Yeul Ma, Korean Medicine (KM)-Based Herbal Drug Development Group, Korea Institute of Oriental Medicine (KIOM), 483 Expo-ro, Yuseong-gu, Daejeon 305-811, Republic of Korea

E-mail: jyma@kiom.re.kr

Key words: herbal cocktail, MA128, malignant tumor, cell death, metastasis, angiogenesis

\section{Introduction}

Malignant tumors consist of cancer cells that usually grow rapidly and spread to other parts of the body via the bloodstream or lymph system by degrading the surrounding tissues and subsequently adapting to form secondary foci known as metastases (1). During the malignant progression, the acquisition of genetic and/or epigenetic alterations causes uncontrolled cell proliferation and resistance to chemotherapy and radiotherapy. In addition, metastatic conversion is one of the main reasons for high mortality rates and a leading cause of the poor clinical outcome of cancer patients, because of its systemic nature and the resistance of disseminated cells to existing therapeutic agents (2). The process of metastasis involves several interdependent processes, including a loss of cell adhesion to the extracellular matrix (ECM), the proteolytic breakdown of tissue barriers, intravasation into the lumina of blood vessels, survival in the circulation, extravasation and the subsequent invasion into new tissues, and metastatic colonization. Therefore, controlling the metastasis and proliferation of already-established tumors is an important therapeutic strategy for the management of malignant tumors $(3,4)$.

Chemotherapy is commonly used to treat cancer. However, current chemotherapy modalities using cytotoxic anti-cancer drugs also destroy normal cells and provide little survival benefit. These modalities also have significant side effects, dose-limiting toxicities and low bioavailability. In many studies, natural herbal medicines control various human diseases, including cancer (5-7). Chinese/Oriental herbal medicines in the form of herbal cocktails have been used to treat a wide range of human diseases and improve the physical strength of patients. Herbal cocktails containing a number of phytochemicals in a single formula have the merit of functioning synergistically by affecting multiple biological and pathological processes, leading to maximal therapeutic effects with minimal side effects $(8,9)$.

Recently, we formulated a novel herbal cocktail termed MA, which is composed of herbal plants that have been used traditionally to control allergic disease and inflammation, including Glycyrrhizae radix, Polygoni cuspidati radix, Sophorae radix, Cnidii rhizoma and Arctii fructus $(10,11)$. To improve the therapeutic efficacy by increasing the absorption and bioavailability of the active components, we fermented MA 
using Lactobacillus rhamnosus (L.rhamnosus) and designated the product of MA128. MA and MA128 are effective for the treatment of asthma by modulating ovalbumin (OVA)-specific cytokines and atopic dermatitis (AD) by reducing IgE production $(10,11)$. In addition, MA128 had significantly increased efficacy against asthma and AD compared with MA. Recently, MA128 was demonstrated to have anti-melanogenic effects by inhibiting tyrosinase activity (12).

In the present study, we examined the anti-cancer effects of MA128 in terms of the induction of cell death and suppression of metastatic potential in highly malignant tumor cells. We also assessed whether the administration of MA128 was useful for the management of malignant tumor cells in mice without exerting adverse effects.

\section{Materials and methods}

Cells and animals. Human fibrosarcoma HT1080 (KCLB no. 10121) and murine melanoma B16F10 (KCLB no. 80008) cells were purchased from the Korean Cell Line Bank (Seoul, Korea) and maintained in RPMI-1640 or Dulbecco's modified Eagle's medium (DMEM; CellGro, Manassas, VA, USA) supplemented with $10 \%$ (v/v) fetal bovine serum (FBS; CellGro), $100 \mathrm{U} / \mathrm{ml}$ penicillin and $100 \mu \mathrm{g} / \mathrm{ml}$ streptomycin (CellGro) at $37^{\circ} \mathrm{C}$ in a humidified incubator with $5 \% \mathrm{CO}_{2}$. Human umbilical vein endothelial cells (HUVECs) were purchased from InnoPharmaScreen (Asan, Korea) at passage 2, maintained in endothelial cell growth medium-2 (EGM-2; PromoCell, Heidelberg, Germany), and used for experiments at passages 3-8. For the animal experiments, female athymic nude mice were purchased from Nara Biotech (Seoul, Korea). Female C57BL/6 mice and male Sprague Dawley rats were obtained from Taconic Farms Inc. (Samtako Bio Korea, Osan, Korea). All animals were housed under controlled conditions using a $12 / 12-\mathrm{h}$ light/dark cycle at $22 \pm 1^{\circ} \mathrm{C}$ and $55 \pm 5 \%$ humidity under specific pathogen-free conditions. All animal experiments were approved by the Animal Care and Use Committee of the Korea Institute of Oriental Medicine (KIOM, Daejeon, Korea), with the reference numbers \#13-42,\#13-48 and \#14-27, and were performed in accordance with the guidelines of the Animal Care and Use Committee at KIOM.

Preparation of the fermented herbal cocktail MA128. Herbs used for the preparation of MA128, including Glycyrrhizae radix, Polygoni cuspidati radix, Sophorae radix, Cnidii rhizoma, and Arctii fructus, were purchased from Yeongcheon Oriental Herbal Market (Yeongcheon, Korea), and all voucher specimens were deposited in the herbal bank in KIOM. The authenticity of the plant species was validated by Professor Ki Hwan Bae (Chungnam National University, Daejeon, Korea). Pure L. rhamnosus KFRI128 cultures were obtained from the Korea Food Research Institute (KFRI) and incubated in MRS medium for $24 \mathrm{~h}$ at $37^{\circ} \mathrm{C}$ as described previously (12). A total of $1,840 \mathrm{~g}$ MA was soaked in 18.41 distilled water (DW) and then heat-extracted for $3 \mathrm{~h}$ at $115^{\circ} \mathrm{C}$ using an extractor (Cosmos-600 Extractor; Gyeonseo Co., Incheon, Korea). After filtration through standard testing sieves (150 $\mu \mathrm{m}$; Retsch, Haan, Germany), the $\mathrm{pH}$ of decoction MA was adjusted to 8.0 using $1 \mathrm{M} \mathrm{NaOH}$. It was then sterilized at $5 \mathrm{~min}$ at $121^{\circ} \mathrm{C}$ using an autoclave. For the fermentation of decoction
MA, $10 \mathrm{ml}$ L. rhamnosus $\left(1 \times 10^{8} \mathrm{CFU} / \mathrm{ml}\right)$ was added to 10 liter decoction MA and incubated at $37^{\circ} \mathrm{C}$ for $48 \mathrm{~h}$. The fermented MA, designated as MA128, was filtered through a $60-\mu \mathrm{m}$ nylon net filter (Millipore, Bedford, MA, USA), freeze-dried and stored in a desiccator at $4^{\circ} \mathrm{C}$. A total of $376 \mathrm{~g}$ MA128 powder was produced and the yield was $20.44 \%$. The freeze-dried MA128 powder was dissolved in $10 \%$ (v/v) DMSO in DW and centrifuged at $14,000 \mathrm{rpm}$ for $10 \mathrm{~min}$. The supernatant was filtered $\left(0.2-\mu \mathrm{m}\right.$, pore size) and kept at $4^{\circ} \mathrm{C}$ prior to use.

Reagents and antibodies. Type A gelatin from porcine skin, fibronectin from human plasma, 3-(4,5-dimethyl-2-thiazolyl)-2,5-diphenyltetrazolium bromide (MTT), phorbol 12-myristate 13-acetate (PMA) and mitomycin C were obtained from Sigma Chemical Co. (St. Louis, MO, USA). Type I collagen solution ( $0.3 \%$, Cellmatrix type I-A) and the growth factor-reduced Matrigel basement membrane matrix were purchased from Nitta Zerachin, Inc. (Osaka, Japan) and BD Biosciences (Bedford, MA, USA), respectively. Antibodies against p21, p27, cyclin B, cyclin D, p38, p-p38 (Thr180/Tyr182), ERK1/2, p-ERK1/2 (Thr202/Tyr204), JNK, p-JNK (Thr183/Tyr185), Akt, p-Akt (Ser473), mTOR, p-mTOR (Ser2481), IкB $\alpha, \mathrm{p}-\mathrm{I} \kappa \mathrm{B} \alpha$ (Ser32/36), p-4E-BP1 (Thr37/46), MMP-9 and tubulin were purchased from Cell Signaling Technology (Danvers, MA, USA). Anti-HIF-1 $\alpha$ antibodies were obtained from BD Biosciences.

Chemicals. For high-performance liquid chromatography (HPLC), HPLC-grade acetonitrile and trifluoroacetic acid (TFA) were purchased from J.T. Baker (Philipsburg, NJ, USA) and Sigma, respectively. Icariin and glycyrrhizin were obtained from the Tokyo Chemical Industry Co. (Tokyo, Japan). Matrine, chlorogenic acid, nodakenin and arctiin were purchased from Faces Biochemical Co. (Wuhan, China). Arctigenin and decursin were obtained from Tocris Biosciences (Bristol, UK) and KFDA (Osong, Korea), respectively.

In vivo assays used to assess the effect of MA128 on tumor growth and pulmonary metastasis. Five-week-old female athymic nude mice were inoculated subcutaneously with $2 \times 10^{6} \mathrm{HT} 1080$ cells/mouse in the femoral region. On day 5, the mice were divided randomly into 3 groups ( $n=5$ per group) and treated daily with saline (control) or MA128 (75 or $150 \mathrm{mg} / \mathrm{kg}$ ) in a volume of $100 \mu \mathrm{l}$ for 12 days. Tumor volume and weight were measured as previously described (13). To induce pulmonary metastasis, C57BL/6 mice were injected intravenously with B16F10 cells ( $3 \times 10^{5}$ cells/mouse) via the tail vein. After being divided randomly into 3 groups ( $n=4$ per group), the mice were administered saline (control) or MA128 at 75 or $150 \mathrm{mg} / \mathrm{kg}$. After daily treatment for 17 days, the mice were sacrificed, their lungs were fixed in Bouin's solution (Sigma), and metastasized black colonies were counted macroscopically. To assess the safety of MA128,5-week-old athymic nude mice and C57BL/6 mice ( $\mathrm{n}=3$ for each group) were treated daily with vehicle (saline) or MA128 (75 or $150 \mathrm{mg} / \mathrm{kg}$ ) for 14 and 15 days, respectively. Body weight was measured daily, and the weights of the major organs, including the liver, heart, lung, spleen and kidneys, were measured at the time of sacrifice. Serological and hematological parameters were analyzed using XL 200 (Erba Diagnostics, Mannheim, Germany) and 
an ADVIA 2120i hematology system (Siemens Healthcare Diagnostics, Tarrytown, NY, USA), respectively.

Cell viability assay. To examine the effects of MA128 on cell proliferation, $5 \times 10^{3}$ cells/well in a 96 -well plate were treated with various concentrations of MA128 $(50-1,000 \mu \mathrm{g} / \mathrm{ml})$ for $48 \mathrm{~h}$, and MTT assays were then performed as previously described (13).

Colony formation assay. To assess anchorage-independent cell growth, $5 \times 10^{4}$ cells were suspended in $2 \mathrm{ml}$ medium containing the indicated concentrations of MA128, 10\% FBS, and $0.3 \%$ agar, and then applied over the bottom agar that had been pre-solidified with $3 \mathrm{ml}$ medium containing 10\% FBS and $0.6 \%$ agar. During incubation, colony formation was observed daily under a phase-contrast microscope, and images were captured.

Adhesion assays on immobilized $F N$ and type I collagen. Cellto-ECM adhesion was measured in 96-well culture plates as reported previously with slight modifications (14). After coating the plates with $50 \mu 1 \mathrm{FN}(5 \mu \mathrm{g} / \mathrm{ml})$ or $0.3 \%$ type I collagen solution overnight at room temperature, the wells were washed with cold PBS, blocked with medium containing $0.3 \%$ BSA (200 $\mu \mathrm{l} /$ well) and then washed again. MA128 pre-treated cells were suspended in serum-free medium at a density of $5 \times 10^{5} / \mathrm{ml}$, plated on FN- or type I collagen-coated wells (200 $\mu \mathrm{l} / \mathrm{well})$, and then allowed to adhere for $1 \mathrm{~h}$ at $37^{\circ} \mathrm{C}$. Unattached cells were removed by washing and the attached cells were stained using $0.2 \%$ crystal violet $/ 20 \%$ methanol (w/v) solution. After staining, the cells were dissolved in $1 \%$ SDS solution, and the spectrophotometric absorbance was measured at $560 \mathrm{~nm}$.

Wound-healing cell migration assay. The cells were pre-incubated with mitomycin $\mathrm{C}(25 \mu \mathrm{g} / \mathrm{ml})$ for $30 \mathrm{~min}$ to inhibit proliferation. Subsequently, they were injured by scraping across the cell monolayer. After washing to remove floating cell debris, the cells were allowed to migrate in the presence of MA128 and monitored under a phase-contrast microscope.

Transwell migration/invasion assays. Migration/invasion assays were performed using Transwell chambers with polyethylene tetraphthalate membranes $(6.5-\mathrm{mm}$ diameter and $8-\mu \mathrm{m}$ pore size) as described previously with slight modifications $(14,15)$. For the invasion assays, the membranes were coated with $50 \mu \mathrm{l}$ Matrigel (diluted in RPMI-1640, 1:8) to form an intervening invasive barrier.

Gelatin zymography. Cells plated in 12-well culture plates at $80 \%$ confluence were pre-incubated with MA128 in serum-free media for $12 \mathrm{~h}$ and then stimulated with $5 \mathrm{nM}$ PMA for an additional $24 \mathrm{~h}$. Conditioned media (CM) were collected and electrophoresed using $8 \%$ SDS-PAGE containing $0.1 \%$ gelatin. After washing, the gels were incubated for $24 \mathrm{~h}$ and then stained and de-stained as previously described $(14,15)$. MMP-9 was detected as a clear $92-\mathrm{kDa}$ band against the blue background.

Tube formation assay. Capillary-like tube formation was assayed using HUVECs, an ECMatrix assay kit (Millipore, Temecula, CA, USA), and $\mu$-Slide Angiogenesis ibiTreat chambers (ibidi GmbH, Germany), as preivously described (16).
HUVECs (5x10 $0^{3}$ cells) were suspended in $50 \mu 1$ MA128-treated HT1080 CM, seeded onto the surface of polymerized ECMatrix, and incubated for $4-8 \mathrm{~h}$ at $37^{\circ} \mathrm{C}$ in an incubator containing $5 \% \mathrm{CO}_{2}$. The cellular tube networks were observed using a phase-contrast microscope and photographed, and the relative tube area was quantified in five fields of view per well.

Rat aortic ring assay. Dorsal aortas isolated from Sprague Dawley rats were cut transversely into 1-mm thick rings. Each aortic ring was then placed in 48-well culture plates pre-coated with $100 \mu 1$ Matrigel. After sealing the rings with $40 \mu 1$ Matrigel, $400 \mu 1$ EGM-2 was added to the wells and the plates were incubated for 3 days to allow microvessel sprouting from the aortic rings. The EGM-2 was then replaced with control or MA128-treated CM, and microvessel outgrowths were observed and photographed for an additional day.

Western blotting. Whole cell lysates were extracted using M-PER Mammalian Protein Extraction reagent (Thermo Scientific, Rockford, IL, USA). Equal amounts of protein were resolved using 8-15\% SDS-PAGE, incubated with specific antibodies, and detected as previously described (13). The band intensities were analyzed using ImageJ software.

Determining VEGF, PDGF and bFGF levels using ELISA. The cells were incubated with the indicated concentrations of MA128 for $48 \mathrm{~h}$. The levels of VEGF, PDGF, and bFGF in control and MA128-treated CM were determined using a Human ELISA Development kit (Peprotech, Rocky Hill, NJ, USA) according to the manufacturer's instructions.

Chromatographic analysis of MA128. The phytochemical profile of MA128 was measured using HPLC analysis on HPLC-DAD (LaChrom Elite, Hitachi High-Technologies Co., Tokyo, Japan), and chromatographic separation was achieved on a Phenomenex Luna C18 column $(4.6 \times 250 \mathrm{~mm}, 5 \mu \mathrm{m})$. A gradient elution of $10 \%$ acetonitrile in deionized water containing $0.05 \%$ TFA (A) and $60 \%$ acetonitrile in deionized water containing $0.05 \%$ TFA (B) was performed as follows: 0-25 min with $0 \% \mathrm{~B} ; 25-100$ min with $0-45 \% \mathrm{~B} ; 100-110 \mathrm{~min}$ with $15-100 \% \mathrm{~B} ; 110-120$ min with $100 \% \mathrm{~B} ; 120-122$ min with $100-0 \% \mathrm{~B}$; and $122-140$ min with $0 \% \mathrm{~B}$. The flow rate and injection volume were $1 \mathrm{ml} / \mathrm{min}$ and $10 \mu 1$, respectively. HPLC chromatograms were obtained using UV at 190-400 nm. Standard (ST), ST-spiked sample (SP), and sample solutions were dissolved and diluted in methanol.

Statistical analysis. Data are presented as mean \pm standard deviation (SDs). The statistical significance of the differences between groups was analyzed using a two-way analysis of variance (ANOVA) and the Student's t-test with SigmaPlot 8.0 software. $\mathrm{P}<0.05$ was considered to indicate significant differences.

\section{Results}

MA128 inhibits the in vivo tumorigenic growth of HT1080 cells with no adverse effects. Prior to determining the anticancer effects of MA128 in athymic nude mice, we assessed whether the repeated administration of 75 or $150 \mathrm{mg} / \mathrm{kg}$ 
Table I. Safety measurement in athymic nude mice after oral administration of 75 or $150 \mathrm{mg} / \mathrm{kg}$ MA128.

\begin{tabular}{|c|c|c|c|}
\hline Variables & Control & $75 \mathrm{mg} / \mathrm{kg}$ & $150 \mathrm{mg} / \mathrm{kg}$ \\
\hline \multicolumn{4}{|l|}{ Body weight (g) } \\
\hline Day 0 & $24.66 \pm 0.46$ & $23.98 \pm 1.59$ & $24.52 \pm 0.48$ \\
\hline Day 14 & $25.05 \pm 0.48$ & $24.54 \pm 1.31$ & $25.23 \pm 0.54$ \\
\hline \multicolumn{4}{|l|}{ Organ weight (g) } \\
\hline Liver & $1.15 \pm 0.04$ & $1.11 \pm 0.11$ & $1.14 \pm 0.04$ \\
\hline Heart & $0.12 \pm 0.01$ & $0.11 \pm 0.01$ & $0.12 \pm 0.01$ \\
\hline Lung & $0.17 \pm 0.01$ & $0.18 \pm 0.01$ & $0.18 \pm 0.02$ \\
\hline Spleen & $0.11 \pm 0.02$ & $0.12 \pm 0.02$ & $0.12 \pm 0.01$ \\
\hline Kidney (L) & $0.15 \pm 0.01$ & $0.12 \pm 0.01$ & $0.14 \pm 0.01$ \\
\hline Kidney (R) & $0.14 \pm 0.01$ & $0.13 \pm 0.01$ & $0.14 \pm 0.02$ \\
\hline \multicolumn{4}{|l|}{ Chemical analysis } \\
\hline GOT (IU/l) & $58.21 \pm 5.46$ & $54.67 \pm 8.33$ & $53.68 \pm 3.61$ \\
\hline GPT (IU/l) & $28.67 \pm 8.08$ & $31.33 \pm 8.08$ & $26.04 \pm 8.72$ \\
\hline BUN (mg/dl) & $22.07 \pm 1.36$ & $23.47 \pm 1.29$ & $19.34 \pm 1.10$ \\
\hline CRE (mg/dl) & $0.47 \pm 0.01$ & $0.53 \pm 0.23$ & $0.48 \pm 0.04$ \\
\hline \multicolumn{4}{|l|}{$\begin{array}{l}\text { Hematological } \\
\text { analysis }\end{array}$} \\
\hline $\mathrm{RBC}\left(\mathrm{x} 10^{6}\right.$ cells $\left./ \mu 1\right)$ & $8.85 \pm 0.41$ & $8.51 \pm 0.49$ & $8.83 \pm 0.18$ \\
\hline $\mathrm{Hb}(\mathrm{g} / \mathrm{dl})$ & $13.77 \pm 0.51$ & $13.69 \pm 0.62$ & $13.95 \pm 0.35$ \\
\hline $\operatorname{PLT}\left(\mathrm{x} 10^{5} / \mu \mathrm{l}\right)$ & $11.67 \pm 0.24$ & $10.71 \pm 2.37$ & $11.27 \pm 1.11$ \\
\hline NEUT (\%) & $38.71 \pm 2.77$ & $31.87 \pm 5.21$ & $33.05 \pm 3.89$ \\
\hline LYM $(\%)$ & $53.51 \pm 4.00$ & $60.57 \pm 8.11$ & $60.55 \pm 4.03$ \\
\hline MONO (\%) & $1.93 \pm 0.75$ & $1.54 \pm 0.21$ & $1.43 \pm 0.14$ \\
\hline
\end{tabular}

Each group of female athymic nude mice $(n=3)$ was administered with 75 or $150 \mathrm{mg} / \mathrm{kg}$ MA128 or the same volume of saline daily. After sacrifice, body and organ weights, and the levels of GOT, GPT, BUN, and CRE were analyzed. GOT, glutamic oxaloacetic transaminase; GPT, glutamic pyruvic transaminase; BUN, blood urea nitrogen; CRE, creatinine. Hematologic parameters were also measured. RBC, red blood cell count; Hb, hemoglobin; PLT, platelet; NEUT, neutrophil; LYM, lymphocyte; MONO, monocyte. Data are presented as mean $\pm \mathrm{SD}$.

MA128 elicited systemic toxicity. The MA128 doses used were according to the amounts administered to human adults $(36.8 \mathrm{~g} / \mathrm{day} / 60 \mathrm{~kg}$ of body weight) and the yield of the extraction. Fourteen days of MA128 administration did not cause death or abnormal behavior. Body and organ weights, the ratios of GOT/GPT and BUN/CRE, and the hematological parameters were comparable between MA128-treated and control mice (Table I), suggesting that MA128 caused no systemic toxicity, including hepatic and renal dysfunction. To assess the inhibitory effects of MA128 on in vivo tumor growth, athymic nude mice ( $\mathrm{n}=5$ per group) inoculated with highly malignant HT1080 cells were treated with saline or 75 or $150 \mathrm{mg} / \mathrm{kg}$ MA128 for 12 days beginning 5 days after tumor inoculation. As shown in Fig. 1A and B, the administration of 75 or $150 \mathrm{mg} / \mathrm{kg}$ MA128 retarded tumor growth successfully and suppressed tumor volume by $\sim 75$ and $85 \%$, respectively, compared with the saline-treated control mice on day 17 . The control mice exhibited a mean tumor weight of $0.441 \pm 0.108 \mathrm{~g}$, whereas the mice treated with 75 and $150 \mathrm{mg} / \mathrm{kg}$ MA128 had
Table II. Safety measurement in C57BL/6J mice after oral administration of 75 or $150 \mathrm{mg} / \mathrm{kg}$ MA128.

\begin{tabular}{lrrr}
\hline Variables & Control & $75 \mathrm{mg} / \mathrm{kg}$ & $150 \mathrm{mg} / \mathrm{kg}$ \\
\hline Body weight (g) & & & \\
$\quad$ Day 0 & $17.43 \pm 0.36$ & $17.26 \pm 0.24$ & $17.85 \pm 0.35$ \\
Day 15 & $19.20 \pm 0.41$ & $19.93 \pm 0.72$ & $20.58 \pm 0.87$ \\
Organ weight (g) & & & \\
Liver & $1.08 \pm 0.04$ & $1.13 \pm 0.03$ & $1.05 \pm 0.07$ \\
Heart & $0.10 \pm 0.02$ & $0.11 \pm 0.01$ & $0.11 \pm 0.01$ \\
Lung & $0.15 \pm 0.01$ & $0.16 \pm 0.02$ & $0.18 \pm 0.01$ \\
Spleen & $0.08 \pm 0.01$ & $0.09 \pm 0.01$ & $0.09 \pm 0.01$ \\
Kidney (L) & $0.12 \pm 0.01$ & $0.13 \pm 0.01$ & $0.12 \pm 0.01$ \\
Kidney (R) & $0.12 \pm 0.01$ & $0.13 \pm 0.01$ & $0.12 \pm 0.01$ \\
Chemical analysis & & & \\
GOT (IU/l) & $52.74 \pm 3.11$ & $53.37 \pm 2.32$ & $54.08 \pm 2.04$ \\
GPT (IU/l) & $29.31 \pm 4.62$ & $27.38 \pm 2.47$ & $27.14 \pm 1.42$ \\
BUN (mg/dl) & $36.52 \pm 1.54$ & $34.78 \pm 1.84$ & $33.49 \pm 2.66$ \\
CRE (mg/dl) & $0.71 \pm 0.16$ & $0.59 \pm 0.15$ & $0.57 \pm 0.21$
\end{tabular}

Hematological

analysis

\begin{tabular}{lrrr}
$\mathrm{RBC}\left(\mathrm{x} 10^{6}\right.$ cells $\left./ \mu \mathrm{l}\right)$ & $9.52 \pm 0.30$ & $9.47 \pm 0.56$ & $9.51 \pm 0.21$ \\
$\mathrm{Hb}(\mathrm{g} / \mathrm{dl})$ & $13.62 \pm 0.30$ & $13.58 \pm 0.08$ & $13.57 \pm 0.08$ \\
$\mathrm{PLT}\left(\mathrm{x} 10^{5} / \mu \mathrm{l}\right)$ & $9.78 \pm 1.96$ & $9.52 \pm 0.18$ & $10.43 \pm 1.37$ \\
NEUT $(\%)$ & $9.78 \pm 1.96$ & $9.52 \pm 0.18$ & $10.43 \pm 1.37$ \\
LYM $(\%)$ & $86.55 \pm 1.85$ & $84.86 \pm 0.29$ & $84.38 \pm 2.22$ \\
MONO $(\%)$ & $0.61 \pm 0.11$ & $0.58 \pm 0.08$ & $0.71 \pm 0.18$ \\
\hline
\end{tabular}

Each group of female C57BL/6 mice $(n=3)$ was administered with 75 or $150 \mathrm{mg} / \mathrm{kg}$ MA128 or the same volume of saline daily. After sacrifice, body and organ weights, and the levels of GOT, GPT, BUN, and CRE were analyzed. GOT, glutamic oxaloacetic transaminase; GPT, glutamic pyruvic transaminase; BUN, blood urea nitrogen; CRE, creatinine. Hematologic parameters were also measured; RBC, red blood cell count; Hb, hemoglobin, PLT, platelet; NEUT, neutrophil; LYM, lymphocyte; MONO, monocyte. Data are presented as mean \pm SD.

tumor weights of $0.139 \pm 0.025 \mathrm{~g}$ and $0.085 \pm 0.045 \mathrm{~g}$, reflecting a decrease of 68.5 and $80.8 \%$, respectively (Fig. 1C). In addition, there were no significant differences in body weight between the control and MA128-treated mice during the experimental period, suggesting that MA128 did not exhibit any severe toxic effects (Fig. 1D).

MA128 decreases cell viability, increases cell cycle-and cell death-associated protein expression, and activates $p 38$ and ERK in HT1080 cells. MTT assays were used to assess the effect of MA128 on the growth of cells treated with specified concentrations of MA128 for $48 \mathrm{~h}$. As shown in Fig. 2A, cell viability was not altered by $50-250 \mu \mathrm{g} / \mathrm{ml}$ MA128 compared with the untreated control cells, whereas treatment with 500 and $1,000 \mu \mathrm{g} / \mathrm{ml}$ MA128 caused a marked decrease in cell viability and induced most cells to shrink and float (Fig. 2B). Western blotting revealed that MA128 increased the levels of the cyclin-dependent kinase inhibitors p21 and p27 in a dose-dependent manner, whereas it decreased the levels of 
A

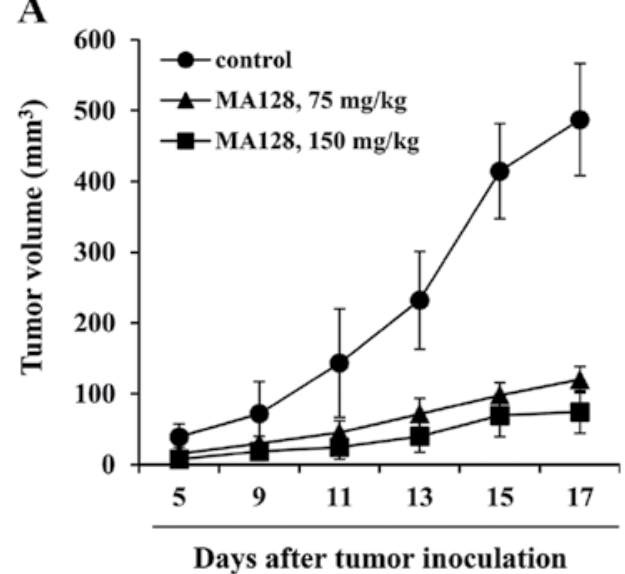

B

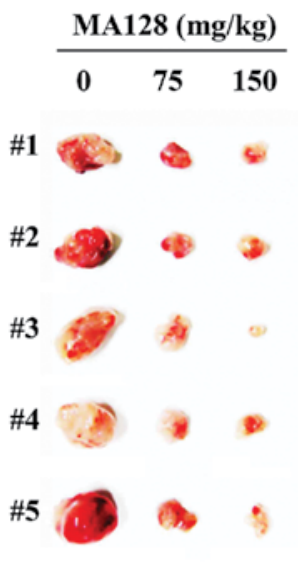

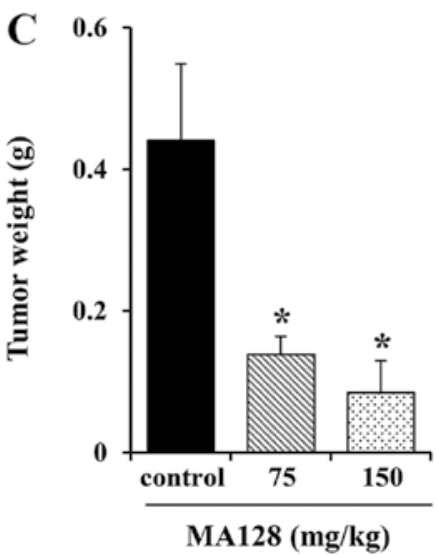

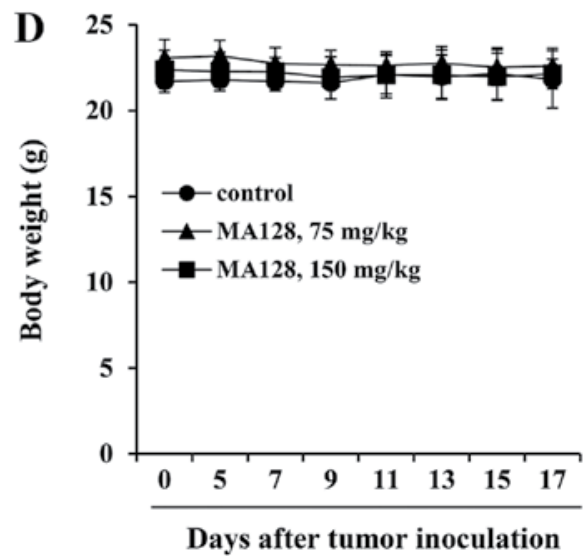

Figure 1. MA128 administration suppresses in vivo tumor growth in a xenograft model efficiently. Athymic nude mice were injected subcutaneously with HT1080 cells (2x10\%/mouse in $200 \mu \mathrm{l}$ PBS). Five days after tumor inoculation, the mice were treated daily with saline (control) or 75 and $150 \mathrm{mg} / \mathrm{kg} \mathrm{MA128}$ for 12 days ( $\mathrm{n}=5$ per group). (A) Tumor volume was determined by measuring the two axes of the tumors, as described in 'Materials and methods'. (B) On day 17 after tumor inoculation, tumors were excised surgically and photographed. (C) The final tumor weight at termination of the experiment was measured, and data are expressed as mean $\pm \mathrm{SD},{ }^{*} \mathrm{P}<0.05$ vs. control (saline). (D) The body weights of the mice were measured every 2 days during the experimental period, and data are presented as mean $\pm \mathrm{SD}$.

cyclin B and D compared with the control cells (Fig. 2C). In addition, MA128 increased the levels of the pro-apoptotic proteins Bad and Bax and decreased the levels of anti-apoptotic Bcl-2 and XIAP (Fig. 2C). It was reported previously that the MAPK signaling pathways can induce cell proliferation or death depending on the stimulus and cell type (17-19). As shown in Fig. 2D, cytotoxic doses of MA128 elevated the levels of phosphorylated p38 and ERK significantly but had little effect on JNK activation. To confirm the roles of p38 and ERK activation in MA128-mediated cell death, the cells were pre-incubated with or without pharmacological inhibitors of p38 (SB203580), ERK (PD98059), or JNK (SP600125) for $1 \mathrm{~h}$ and then treated with MA128 for 48 h. As shown in Fig. 2E, SB203580 and PD98059 moderately protected MA128-treated cells from death by $\sim 50 \%$, whereas SP600125 had little effect. This result suggested that $\mathrm{p} 38$ and ERK activation play roles in MA128-mediated cell death.

MA128 inhibits the in vivo pulmonary metastasis of B16F10 cells with no adverse effects. Prior to assessing the anti-metastatic effects of MA128 in C57BL/6 mice, the safety of MA128 treatment was assessed over a 15 -day period. As shown in Table II, MA128 did not induce any adverse effects, such as loss of body weight or differences in organ weights. In addition, there were no critical differences in the serological or hematological parameters between MA128-treated and control mice. After confirming safety, we evaluated whether MA128 reduced the pulmonary colonization of B16F10 cells injected intravenously into the tail vein of $\mathrm{C} 57 \mathrm{BL} / 6$ mice. As shown in Fig. 3A and B, B16F10 cells metastasized to the lungs of control mice and formed a considerable number of black colonies $(939.81 \pm 83.98)$. However, the incidence of metastatic colonies in mice treated with 75 and $150 \mathrm{mg} / \mathrm{kg}$ MA128 was decreased significantly by $\sim 57.9(395.33 \pm 75.72)$ and $61.1 \%$ (365.67 \pm 105.19$)$, respectively, compared with the control mice. These results suggested that MA128 intake suppressed the pulmonary metastasis of B16F10 cells efficiently without causing systemic toxicity. To examine the anti-metastatic effects of MA128 in vitro, we monitored the cell-to-ECM adhesion, migration, and invasion of B16F10 cells in the presence or absence of MA128. Pre-treatment with MA128 inhibited the attachment of cells to FN and collagen in a dose-dependent manner (Fig. 3C). In the Transwell culture system, serum-induced migration and invasion were markedly 


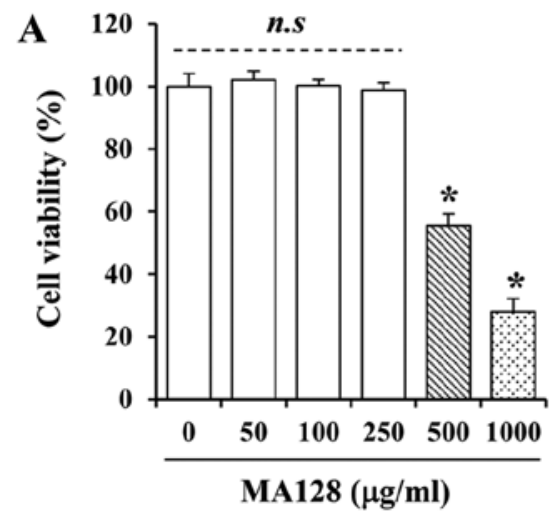

C

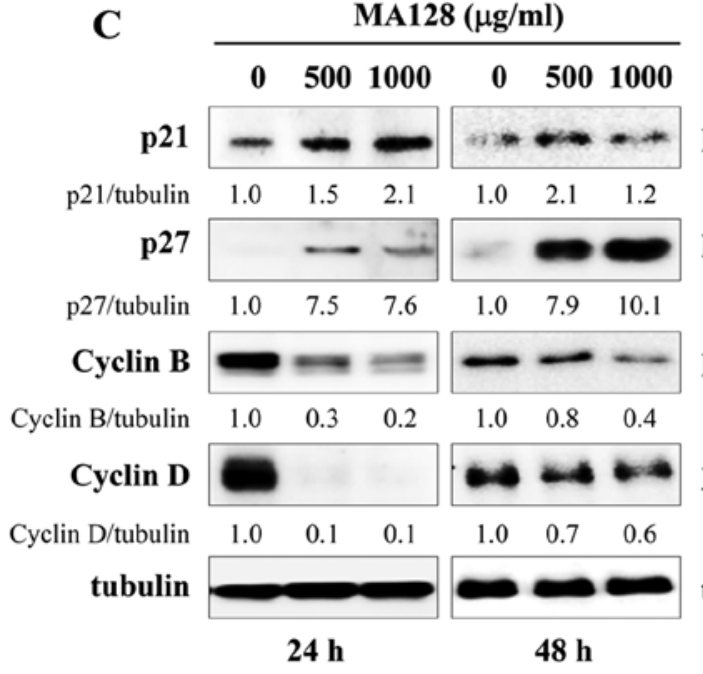

B

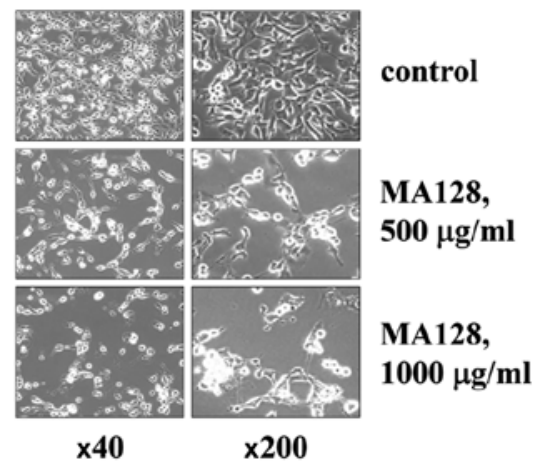

D
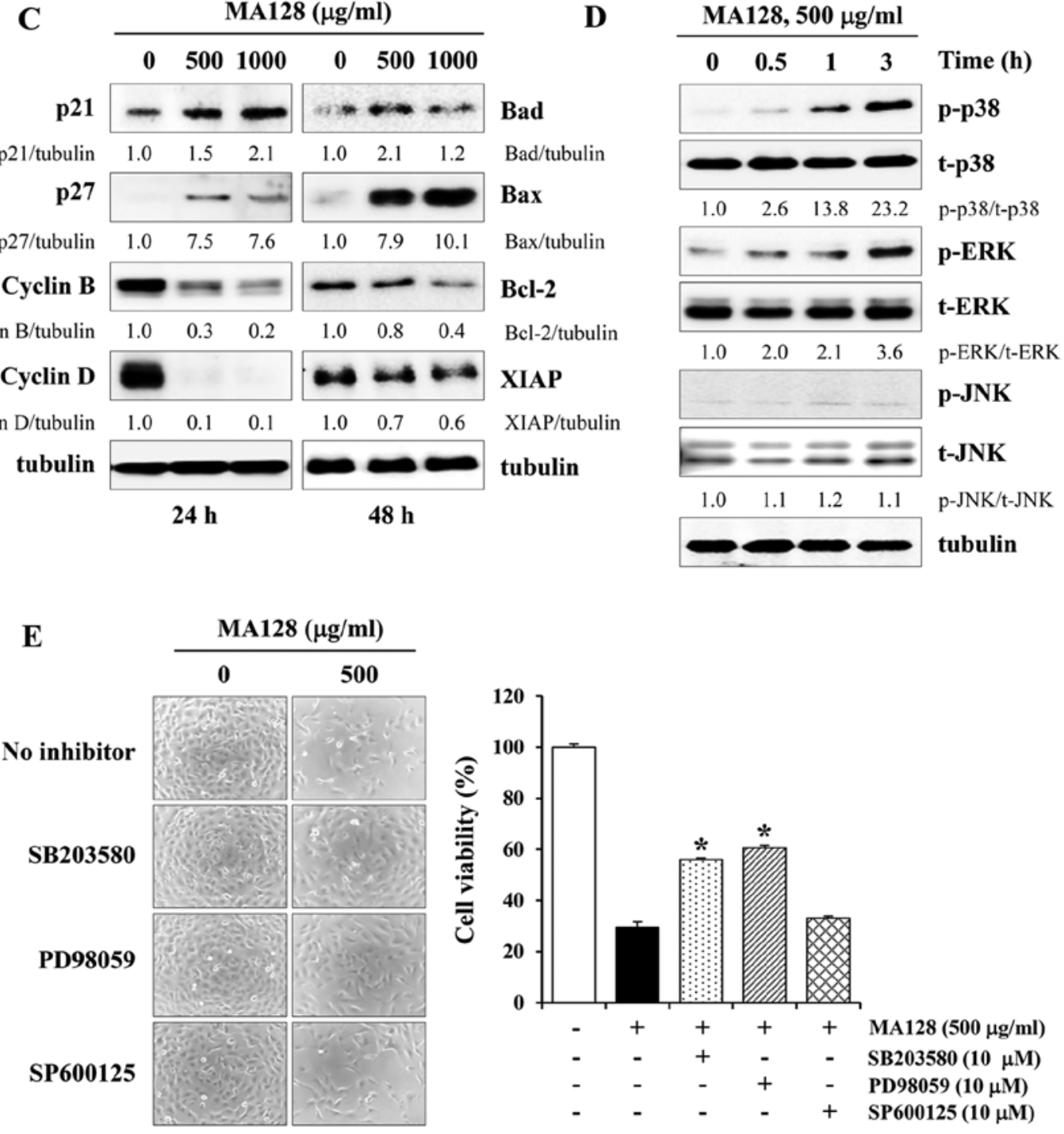

Figure 2. MA128 induces cell death and activates p38 and ERK in a dose-dependent manner. (A) HT1080 cells were treated with the indicated concentrations of MA128 for $48 \mathrm{~h}$, and cell viability was then determined using MTT assays. Data are presented as means \pm SD of triplicate assays. "P<0.05 vs. untreated control; n.s., non-significant. (B) HT1080 cells were treated with MA128 for $48 \mathrm{~h}$ and then observed under an inverted microscope (magnification, x40 and $\mathrm{x} 200$ ). (C) The levels of cell cycle- and cell death-associated proteins were examined in MA128-treated HT1080 cells by western blotting. (D) After treatment with $500 \mu \mathrm{g} / \mathrm{ml}$ MA128 for $0.5,1,3$, and $6 \mathrm{~h}$, the levels of total and phosphorylated MAPKs were detected by western blotting. The band intensities relative to the untreated control cells were determined after normalization to tubulin expression. (E) After pre-incubation with or without specific inhibitors, the cells were treated with $500 \mu \mathrm{g} / \mathrm{ml}$ MA128 for $48 \mathrm{~h}$, and cell viability was determined using MTT assays. Data obtained from two independent experiments are presented as mean $\pm \mathrm{SD}$. ${ }^{*} \mathrm{P}<0.05$ vs. no inhibitor.

reduced by MA128 to $10.6-25.8$ and 15.7-41.2\% in the control cells, respectively (Fig. 3D).
MA128 suppresses PMA-induced migration and invasion by suppressing MMP-9 activity and blocking $N F-\kappa B$ activation 
A

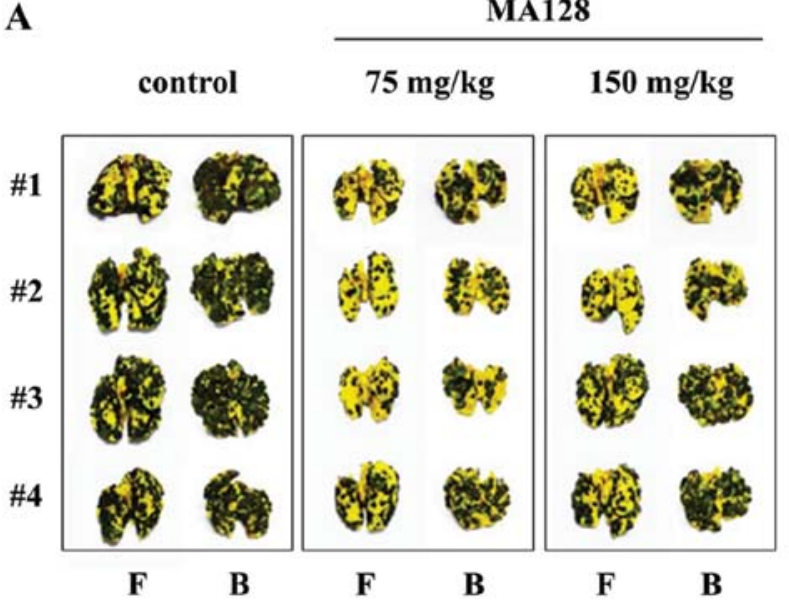

B

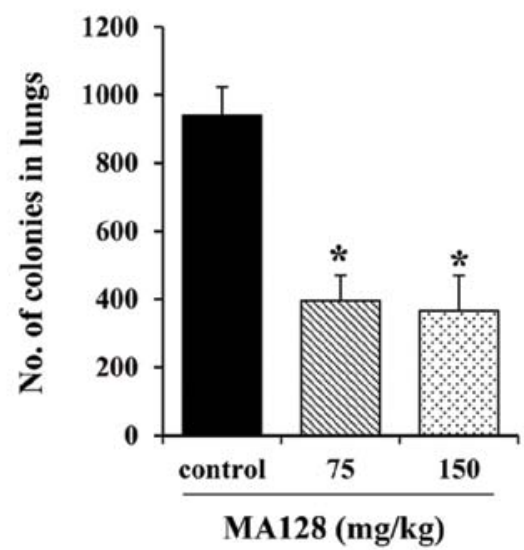

C
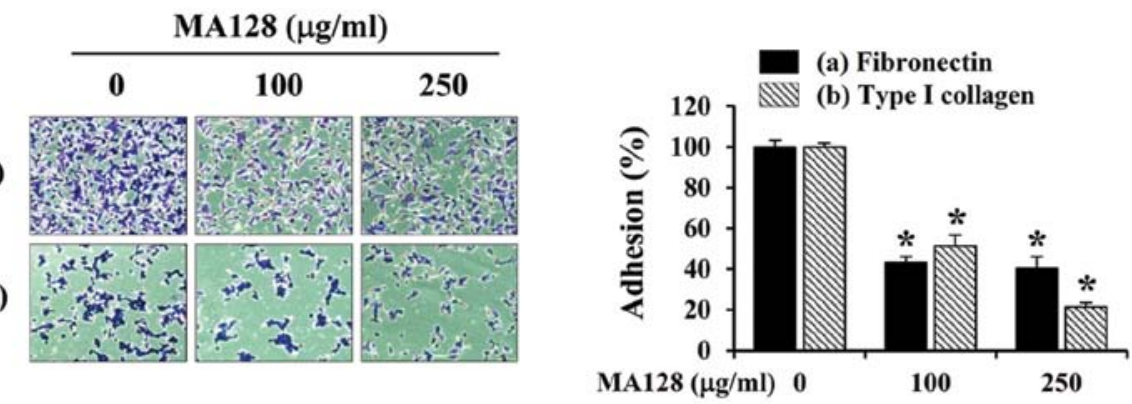

D
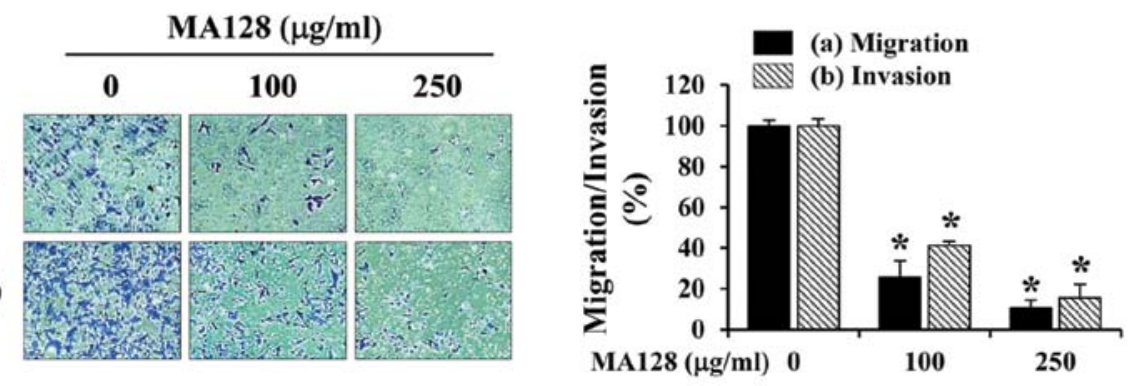

Figure 3. MA128 markedly inhibits the in vivo pulmonary metastasis and in vitro adhesion, migration, and invasion of B16F10 cells at non-toxic concentrations. (A) Cells (3x105/mouse in $200 \mu \mathrm{lBS})$ were injected into the tail vein of C57BL/6 mice, which were then treated daily with 75 and $150 \mathrm{mg} / \mathrm{kg}$ MA128 ( $\mathrm{n}=4$ per group). On day 17, the mice were sacrificed, and the $\mathrm{F}$, front and $\mathrm{B}$, back of the lungs were photographed. (B) Black colonies on the lung surface were counted macroscopically, and data are presented as mean $\pm \mathrm{SD}$. ${ }^{*} \mathrm{P}<0.05$ vs. control (saline). (C) B16F10 cells pre-incubated with or without MA128 were seeded in FN- or collagen-coated wells, incubated for $1 \mathrm{~h}$, and then washed to remove unattached cells. (D) B16F10 cells pre-incubated with or without MA128 were added into the upper well of Transwell chambers and incubated for $24 \mathrm{~h}$ (migration) or $48 \mathrm{~h}$ (invasion). (C and D) Cells were stained with $0.2 \%$ crystal violet $/ 20 \%$ methanol (w/v) solution, and the relative degrees of adhesion, migration, and invasion were calculated. Data are presented as mean $\pm \mathrm{SD}$. ${ }^{*} \mathrm{P}<0.05$ vs. untreated control.

in HT1080 cells. To clarify the anti-metastatic mechanism of action of MA128, HT1080 cells and PMA were used under the conditions as previously described (20-22). At the non-toxic concentrations of 50-250 $\mu \mathrm{g} / \mathrm{ml}$, MA128 treatment prevented HT1080 anchorage-independent colony formation (Fig. 4A) and the adhesion to FN and collagen (Fig. 4B) in a dose-dependent manner. Results of the wound-healing assay showed that the control HT1080 cells repaired the wounded area efficiently to $\sim 35$ and $70 \%$ levels after 18 and $40 \mathrm{~h}$, respectively. By contrast, MA128 treatment inhibited wound repair significantly, allowing only $\sim 10$ and $15 \%$ healing at 18 and $40 \mathrm{~h}$, respectively (Fig. 4C). In addition, the ability of HT1080 cells to undergo Transwell migration and invasion was markedly increased by PMA stimulation, whereas MA128 almost completely inhibited migration and invasion under PMA-stimulated conditions (Fig. 4D), suggesting that MA128 exerted potent anti-metastatic effects. To elucidate the mechanism by which MA128 inhibited the metastatic potential, we examined whether MA128 suppressed the expression and activity of MMP-9, which is essential for facilitating tumor metastasis by degrading the surrounding ECM.

As shown in Fig. 5A, PMA strongly induced the gelatinolytic activity and secretion of MMP-9, as determined using gelatin zymography and western blotting. By contrast, treatment with MA128 markedly inhibited the PMA-induced increase in MMP-9 activity and expression in a dose-dependent 
A
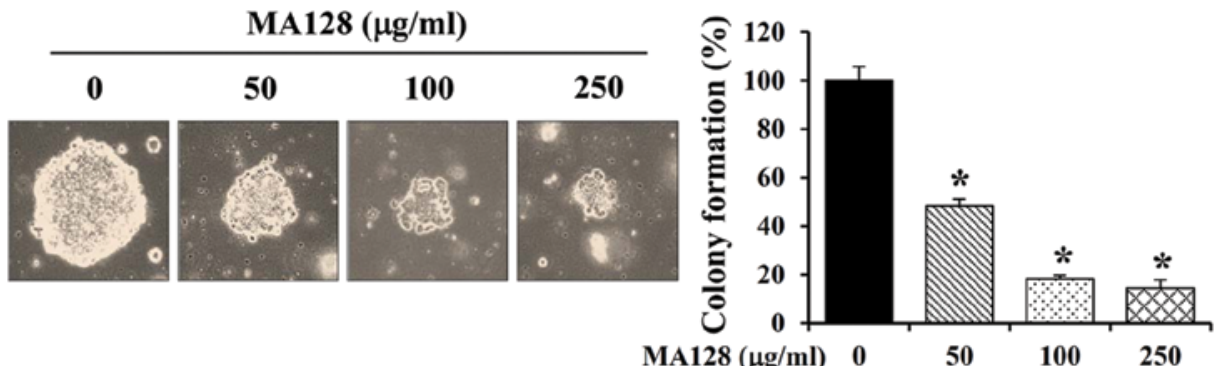

B

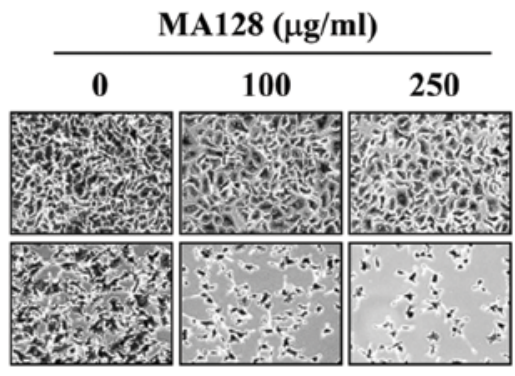

MA128 $(\mu \mathrm{g} / \mathrm{ml}) \quad \mathbf{0} \quad \mathbf{5 0} \quad \mathbf{1 0 0} \quad \mathbf{2 5 0}$

(a)

(b)

C

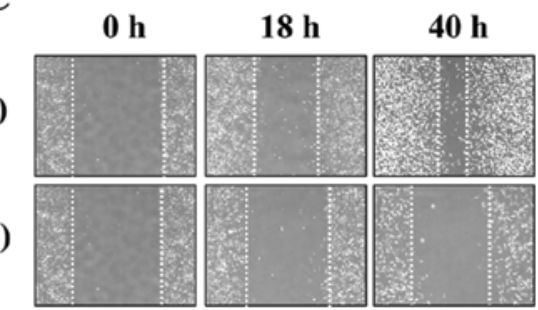

D
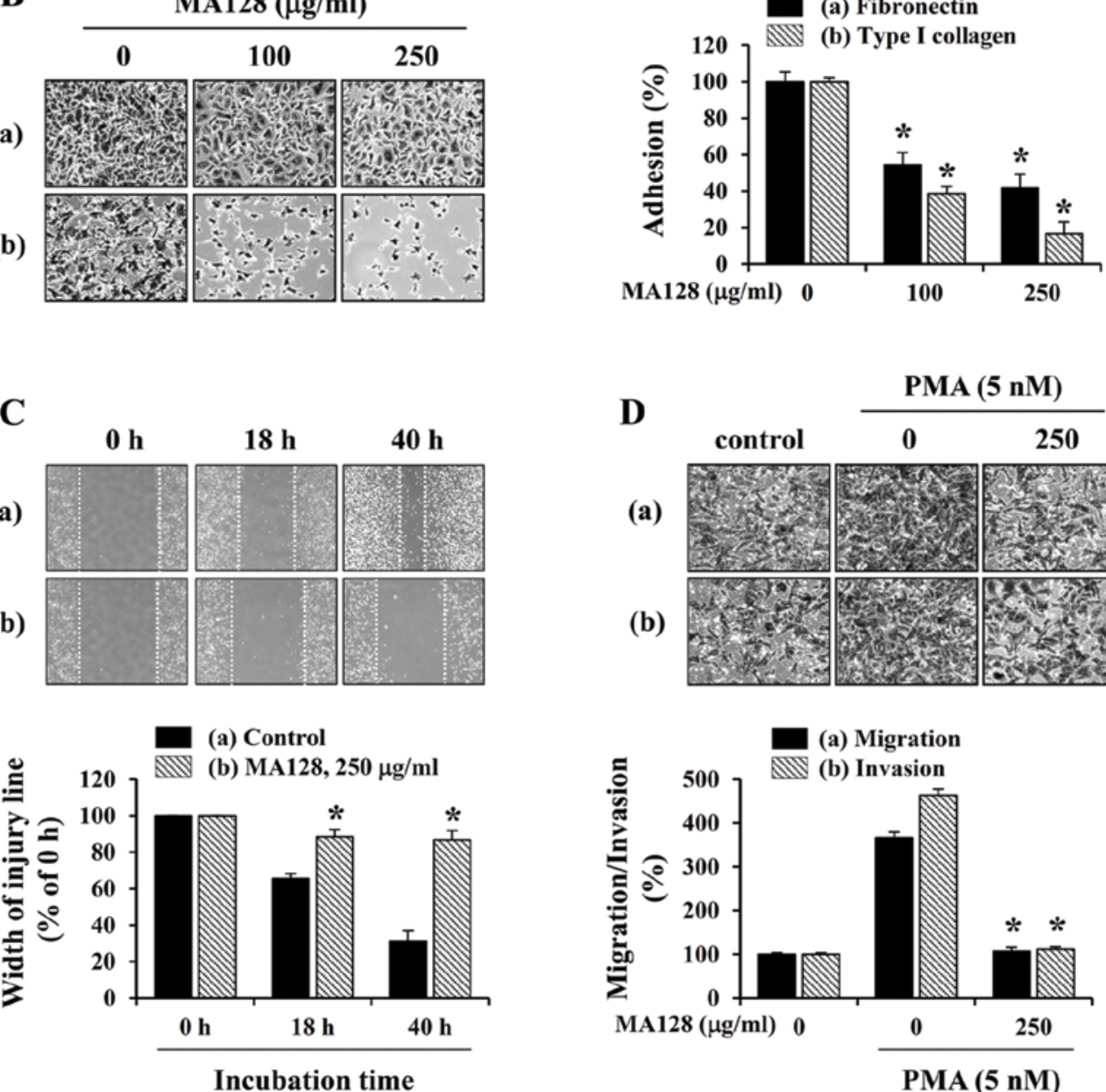

(a)
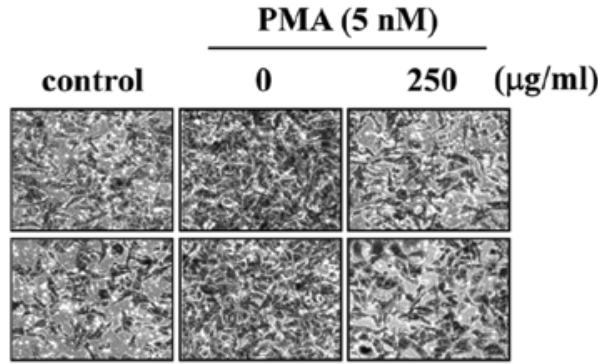

(b)

(a) Migration

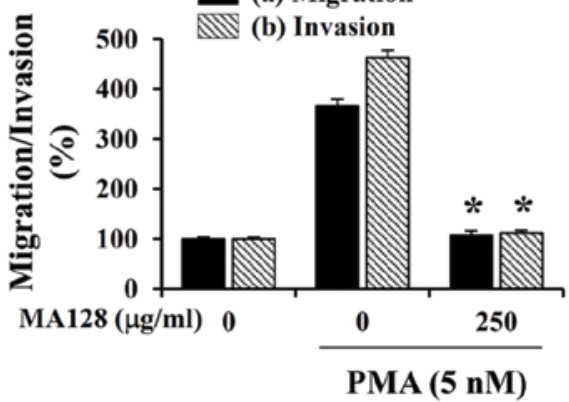

Figure 4. Non-toxic concentrations of MA128 suppress the metastatic potential of HT1080 cells. (A) Anchorage-independent cell growth in soft agar containing non-toxic concentrations of MA128 was measured. After incubation for 14 days, the diameters of 10 representative colonies were measured. Data are presented as mean \pm SD. (B) HT1080 cells pre-incubated with or without MA128 were seeded in FN- or collagen-coated wells, incubated for $1 \mathrm{~h}$, and then washed to remove unattached cells. Adhered cells were stained with $0.2 \%$ crystal violet/20\% methanol (w/v) solution. (C) After generating wounds on confluent cell monolayers, the cells were incubated in medium containing $10 \%$ FBS with or without $250 \mu \mathrm{g} / \mathrm{ml} \mathrm{MA} 128$, and migration was monitored under a phase-contrast microscope at the indicated time points. Based on the width of the injury line at $0 \mathrm{~h}$, the relative widths were calculated. Data are presented as mean \pm SD. ${ }^{*} \mathrm{P}<0.05$ vs. untreated control. (D) The effects of MA128 on PMA-induced migration and invasion were determined using Transwell chambers. The cells were pre-incubated with or without MA128 for $12 \mathrm{~h}$, added into the upper wells of Transwell chambers, and then incubated with 5 nM PMA for $12 \mathrm{~h}$ (migration) or $24 \mathrm{~h}$ (invasion). Migrated and invaded cells were stained and images captured. The relative values were calculated using Image J and shown as mean \pm SD. ${ }^{*} \mathrm{P}<0.05$ vs. PMA with no MA128.

manner. Since the transcription factor NF- $\mathrm{kB}$ is critical for MMP expression and invasion in various cancer cells $(23,24)$, we examined the effects of MA128 on PMA-induced NF- $\kappa B$ activation. As shown in Fig. 5B, PMA treatment markedly increased the phosphorylation and degradation of $\mathrm{I} \kappa \mathrm{B} \alpha$ in HT1080 control cells. However, MA128 significantly inhibited PMA-induced IкB $\alpha$ phosphorylation and degradation. Consequently, the $\mathrm{p}-\mathrm{I} \kappa \mathrm{B} \alpha / \mathrm{I} \kappa \mathrm{B} \alpha$ ratio was much lower in the
MA128-treated cells compared with that in the control cells. Taken together, these results suggested that non-toxic doses of MA128 suppress the metastatic potential of HT1080 cells by reducing MMP-9 activity and inhibiting NF- $\kappa \mathrm{B}$ activation.

MA128 attenuates tumor-induced angiogenesis by reducing the production of angiogenic factors. Tumor-induced angiogenesis, the formation of new blood vessels from existing 
A

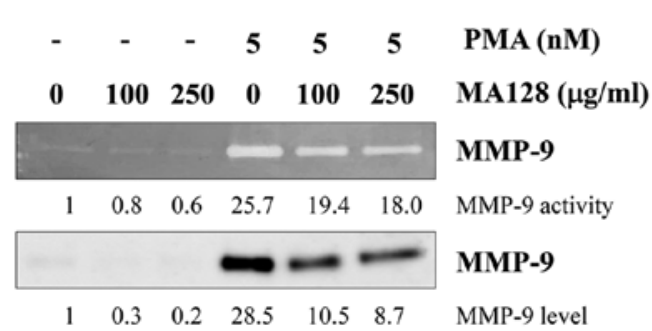

B

PMA stimulation (5 nM)

\begin{tabular}{|c|c|c|c|c|c|c|c|c|}
\hline $\mathbf{0}$ & 15 & 30 & 60 & $\mathbf{0}$ & 15 & 30 & 60 & Time (min) \\
\hline - & - & - & - & + & + & + & + & MA128 $(250 \mu \mathrm{g} / \mathrm{ml})$ \\
\hline$=$ & $=$ & $=$ & - & $\longrightarrow$ & $m$ & $=$ & 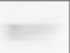 & p-ІкВ $\alpha$ \\
\hline 1 & 0.9 & 3.1 & 1.1 & 0.7 & 0.6 & 1.7 & 0.2 & p-IאB $\alpha /$ tubulin \\
\hline 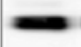 & - & - & $=$ & 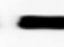 & - & 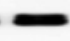 & - & $\mathbf{I} \boldsymbol{B} \mathbf{B} \boldsymbol{\alpha}$ \\
\hline 1 & 0.7 & 0.7 & 0.2 & 0.9 & 0.9 & 0.8 & 0.2 & I $\mathrm{BB} \alpha /$ tubulin \\
\hline 1 & 1.3 & 4.2 & 5.3 & 0.7 & 0.7 & 2.2 & 1.0 & $\mathrm{p}-\mathrm{I \kappa B} \alpha / \mathrm{I} \kappa \mathrm{B} \alpha$ \\
\hline
\end{tabular}

Figure 5. MA128 decreases PMA-induced gelatinolytic activity and the expression of MMP-9 via the suppression of NF-kB activation. (A) HT1080 cells were pretreated with MA128 for $12 \mathrm{~h}$ and then incubated for $24 \mathrm{~h}$ with or without $5 \mathrm{nM}$ PMA. CM was collected and analyzed for gelatinolytic activity and MMP-9 levels using gelatin zymography and western blotting, respectively. (B) Control and MA128-treated HT1080 cells were stimulated with $5 \mathrm{nM}$ for the indicated time points, and the levels of phosphorylated and degraded IкB $\alpha$ were analyzed by western blotting. The band intensities were measured using ImageJ.

vasculature, is induced by tumor cells and is critical for sustained tumor growth and metastasis (25-27). It has been reported that supernatants harvested from various tumor cells triggered an angiogenic response. Therefore, we examined the ability of HUVECs to form network structures on Matrigel after incubation with control or MA128-treated CM derived from HT1080 cell cultures. As shown in Fig. 6A, control CM stimulated HUVECs to assemble into tube-like structures on Matrigel, whereas MA128-treated CM significantly reduced tube formation in terms of the number, length, and area of capillary-like structures in a dose-dependent manner. Using ex vivo angiogenesis assay, we assessed microvessel sprout formation in rat aortic rings, after incubation with control or MA128-treated CM from HT1080 cells. As reported previously, control CM from HT1080 cell cultures triggered microvessel sprouting around the aortic rings (16), whereas the length of the sprouting microvessels around the aortic rings incubated with MA128-treated CM was markedly shorter than that with control CM (Fig. 6B). As tumor-induced angiogenesis is affected by tumor cell-produced angiogenic factors, the levels of pro-angiogenic factors, including VEGF- $\alpha$, PDGF and bFGF, were measured in the control and MA128-treated CM from HT1080 cells. As shown in Fig. 6C, ELISA revealed that MA128 treatment significantly reduced the production of angiogenic factors in a dose-dependent manner (Fig. 6C). Angiogenic factors are immediate downstream targets of HIF-1 $\alpha$ (28). Therefore, we assessed the effect of MA128 on HIF-1 $\alpha$ production. MA128 reduced $\mathrm{CoCl}_{2}$-stimulated HIF-1 $\alpha$ protein accumulation, which was accompanied via inhibition of Akt/mTOR/4E-BP-1 signaling (Fig. 6D). This result suggested that MA128 decreased tumor-induced angiogenesis by inhibiting the production of angiogenic factors via the suppression of HIF-1 $\alpha$ accumulation.

Identifying the main components in MA128 using HPLC. HPLC identified eight phytochemicals in MA128: matrine, chlorogenic acid, nodakenin, arctiin, icariin, arctigenin, glycyrrhizin and decursin. To achieve the desired separation, a gradient elution of water and acetonitrile was applied. TFA was added to advance the peak shape and inhibit peak tailing, and the UV wavelengths of the eight components were adjusted based on the maximum UV spectra absorption of each component. As shown in Fig. 7, matrine, nodakenin, arctiin, icariin, arctigenin, and decursin were detected at $203 \mathrm{~nm}$, and chlorogenic acid and glycyrrhizin were detected at 254 and $320 \mathrm{~nm}$, respectively. Each component in MA128 was identified by comparing the retention time $\left(t_{R}\right)$ and UV spectra with known data. Profiles corresponding to matrine $\left(1, t_{R} 5.3 \mathrm{~min}\right)$, chlorogenic acid $\left(2, t_{R} 11.3 \mathrm{~min}\right)$, nodakenin ( $\left.3, t_{R} 52.7 \mathrm{~min}\right)$, arctiin $\left(4, t_{R} 76.6 \mathrm{~min}\right)$, icariin $\left(5, t_{R} 89.1 \mathrm{~min}\right)$, arctigenin $\left(6, t_{R} 105.2 \mathrm{~min}\right)$, glycyrrhizin $\left(7, t_{R} 109.6 \mathrm{~min}\right)$, and decursin $\left(8, t_{R} 119.7 \mathrm{~min}\right)$ were identified in MA128.

\section{Discussion}

It has been reported that interfering with critical steps of cancer growth and progression, including metastasis and angiogenesis, using naturally occurring herbal agents and phytochemicals is important for reducing the morbidity and mortality of cancer patients $(7,29,30)$. Properly formulated herbal cocktails have the advantage of synergism among individual herbs and improved therapeutic efficacy by targeting various cell pathways while minimizing side effects. Although Chinese/Oriental herbal medicine has long been used to control malignancies, quality control of the active ingredients, safety assessment and elucidation of the mechanism of action must be accompanied by medicinal efficacy for their therapeutic value in modern medicine (31). Rigorous and systematic cell-based in vitro and in vivo pre-clinical animal studies that support their efficacy, safety, and underlying mechanisms are essential for transforming traditional herbal practice into 'evidence-based medicine'.

We developed a novel mixture of medicinal herbs known as MA128, comprising several herbs that have been used traditionally to treat inflammatory and allergic diseases and have been fermented with L. rhamnosus to improve their therapeutic potential. In previous studies, we demonstrated that the oral administration of MA and MA128 ameliorated the major clinical signs of AD including erythema/darkening, edema, excoriations and dryness in AD-induced BALB/c mice. It also exhibited anti-asthmatic effects by suppressing the infiltration of eosinophils into the airway and blood and 
A

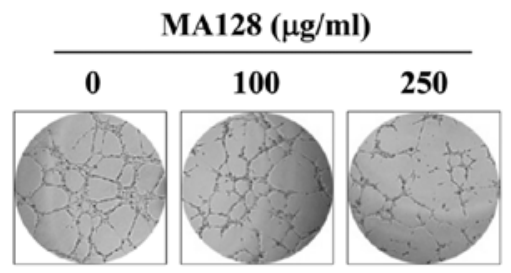

HT1080-CM

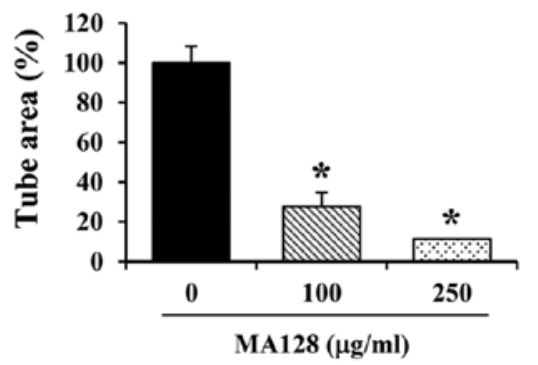

C
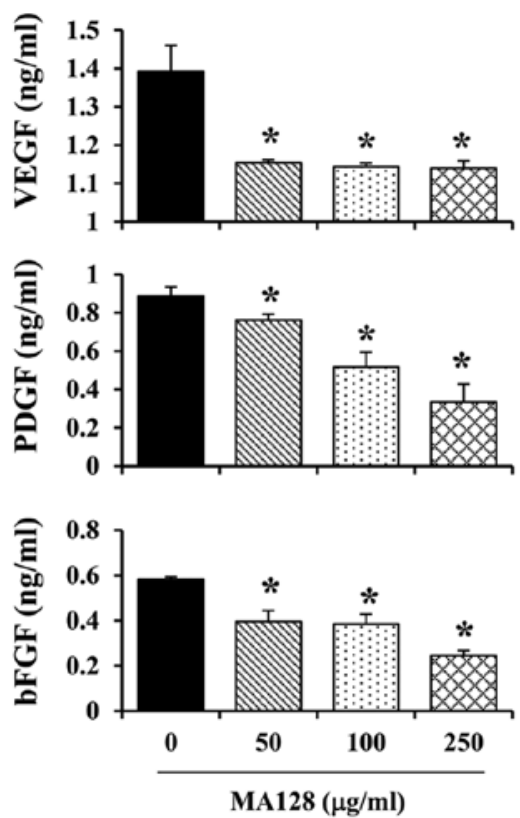

B

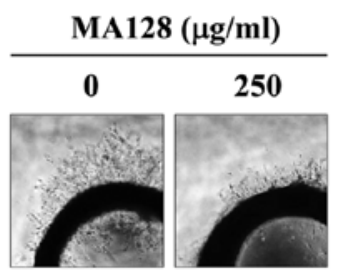

HT1080-CM

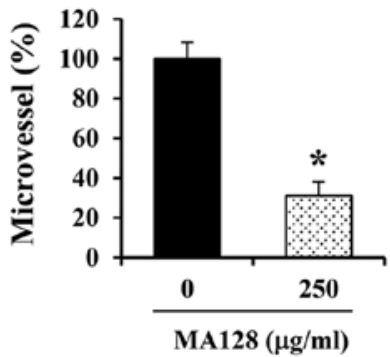

D

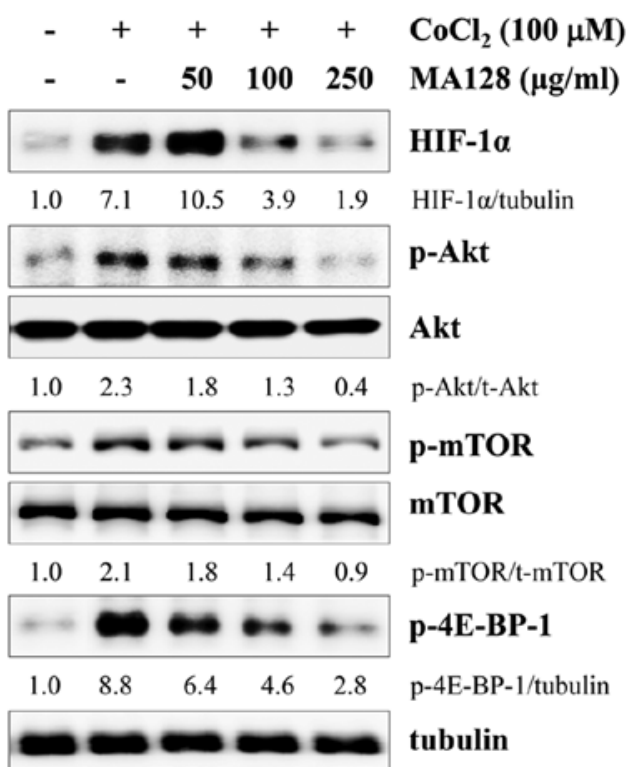

Figure 6. MA128 suppresses tumor-induced angiogenesis. (A) The capillary-like tube formation of HUVECs induced by control or MA128-treated CM isolated from HT1080 cells was examined. The total tube area was measured using ImageJ and shown as the mean \pm SD of three random fields. "P<0.05 vs. control CM. (B) Freshly prepared aortic rings were placed in Matrigel-coated 48-well culture plates and incubated with control or MA128-treated CM harvested from HT1080 cells. After 7 days, the microvessels sprouting from rat aortic rings was photographed, and the length of the microvessels was measured. Data are presented as the mean \pm SD of three random fields. "P<0.05 vs. control CM. (C) HT1080 cells were treated with or without MA128, and the levels of VEGF- $\alpha$, PDGF and $\mathrm{bFGF}$ in the $\mathrm{CM}$ were determined using ELISA. Data are presented as the mean $\pm \mathrm{SD}$ of assays performed in triplicate. ${ }^{*} \mathrm{P}<0.05 \mathrm{vs}$. untreated control. (D) HT1080 cells pre-incubated with or without MA128 were stimulated with $100 \mu \mathrm{M} \mathrm{CoCl}_{2}$ for $6 \mathrm{~h}$. The levels of HIF-1 $1 \alpha$, phosphorylated Akt, mTOR, and 4E-BP-1 were then measured by western blotting, and the relative ratios were calculated after normalization to tubulin using ImageJ.

reducing allergic airway inflammation in asthma-induced $\mathrm{BALB} / \mathrm{c}$ mice. In addition, the therapeutic efficacy of MA128 in these two experimental models was increased significantly by fermentation $(11,21)$.

In the present study, we have demonstrated that MA128 inhibits the proliferation, metastasis, and tumor-induced angiogenesis of malignant tumor cells in vitro and in vivo, with no apparent side effects. This finding suggests that MA128 may be used as a safe and effective remedy for controlling malignant tumor cells. In previous studies, individual herbs in MA128, including Sophorae radix, Polugoni cuspidati radix, Arctii fructus, and Angelica gigantis radix, were shown to elicit anti-cancer effects by inhibiting cell proliferation and inducing apoptosis (32-35). We used HPLC to identify eight phytochemicals in MA128. Of these, previous studies have shown that decursin inhibits the lung metastasis of CT-26 murine colon carcinoma by targeting MMP-9 activity via the suppression of ERK and JNK phosphorylation, inducing cell cycle arrest and apoptosis in human carcinomas, including prostate, colon, and bladder, and by inhibiting VEGF-induced angiogenesis, suggesting that it plays a crucial role in mediating anti-cancer activity (36-38). In addition, matrine and glycyrrhizin inhibited cell proliferation and induced apoptosis in many human carcinomas (39-41), whereas matrine reduced 

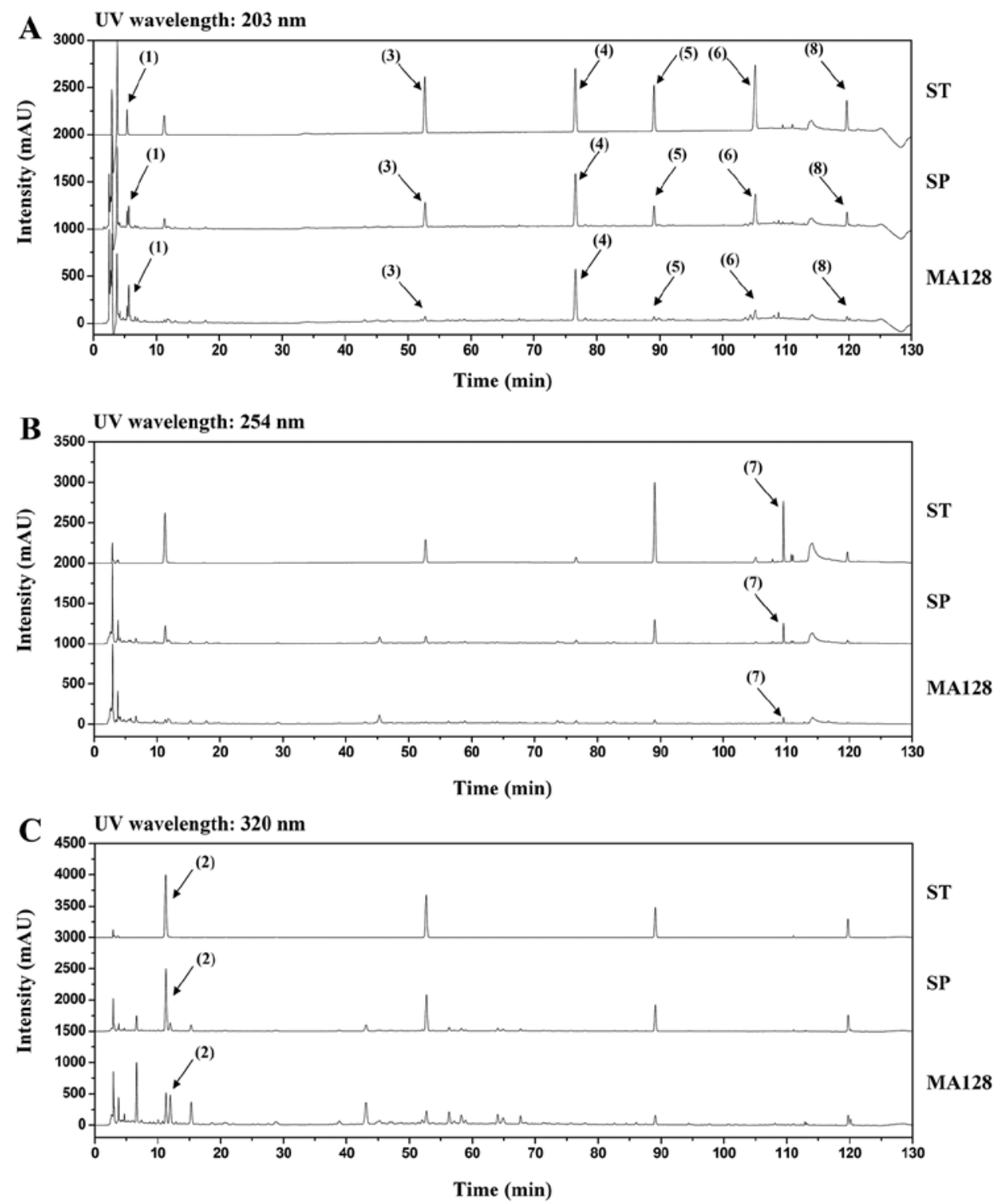

Figure 7. Chromatograms of eight major standard compounds (ST), spiked samples (SP), and MA128 identified at UV wavelengths of (A) $203 \mathrm{~nm}$, (B) $254 \mathrm{~nm}$, and (C) $320 \mathrm{~nm}$. Matrine (1), chlorogenic acid (2), nodakenin (3), arctiin (4), icariin (5), arctigenin (6), glycyrrhizin (7) and decursin (8) were identified.

the invasion of A375 human malignant melanoma cells (42). Icariin exerted negative effects on the invasion and migration of BGC-823 human gastric cancer cells by reducing Rac1 and VASP expression (43). It also induced apoptosis in SMMC-7721 human hepatoma cells by generating ROS via the activation of JNK (44). These results suggest that MA128 has the potential to suppress cell proliferation, migration, invasion, and angiogenesis via these active components.

Tumor-induced angiogenesis is dependent on the release of pro-angiogenic factors, such as VEGF, PDGF, bFGF, angiopoietin and MMPs by tumor cells. These factors in turn stimulate existing blood vessels to initiate angiogenesis. Without angiogenesis, tumor masses are restricted to a few millimeters due to a lack of oxygen and nutrients, and they cannot escape into the circulation to metastasize (25). It has been reported that MMP-2, MMP-9, and VEGF expression levels were positively correlated with tumor size, lymphatic and venous invasion, and lymph node metastasis, as well as malignant progression (45). In the present study, treatment with non-toxic concentrations of MA128 decreased the production of MMP-9 and pro-angiogenic factors in CM significantly by inhibiting $N F-\kappa B$ activation and HIF- $1 \alpha$ accumulation. Therefore, the proteolytic activity against gelatin, migration/invasion through Matrigel, and tumor-induced angiogenesis were decreased in MA128-treated cells compared with the control cells. In addition, higher concentrations of MA128 induced cell death efficiently by inducing p38 and ERK phosphorylation. In animal models, the oral administration of 75 and $150 \mathrm{mg} / \mathrm{kg}$ MA128 markedly suppressed the growth of HT1080 cells and pulmonary metastasis of B16F10 cells. Safety evaluation of MA128 in athymic nude mice and C57BL/6 mice revealed that the oral administration of 75 and $150 \mathrm{mg} / \mathrm{kg}$ MA128 during the experimental period did not cause any systemic toxicity with respect to body weight loss, organ abnormalities, or changes in serological/hematological parameters. This finding suggests that MA128 is a safe and effective cancer treatment. Of note, none of the individual herbs exhibited anti-cancer activities in HT1080 cells at the concentrations present in 
MA128, suggesting that the herbs present in MA128 exerted synergistic and reciprocal effects.

In summary, the current data clearly demonstrate that higher concentrations of MA128 induced cell death, primarily via p38 and ERK activation, and non-toxic concentrations of MA128 suppressed metastatic activity by inhibiting the production of MMP-9 and pro-angiogenic factors in malignant tumor cells. Furthermore, MA128 exhibited potent anti-cancer efficacy against tumor growth and pulmonary metastasis in mice with no adverse effects. These results collectively suggest that MA128 is a safe and efficacious herbal remedy against malignant tumors.

\section{Acknowledgements}

This study has been supported by the grant K14050 awarded to the Korea Institute of Oriental Medicine (KIOM) from the Ministry of Science, ICT and Future Planning (MSIP), Republic of Korea.

\section{References}

1. Liotta LA, Steeg PS and Stetler-Stevenson WG: Cancer metastasis and angiogenesis: An imbalance of positive and negative regulation. Cell 64: 327-336, 1991.

2. Maddika S, Ande SR, Panigrahi S, Paranjothy T, Weglarczyk K Zuse A, Eshraghi M, Manda KD, Wiechec E and Los M: Cell survival, cell death and cell cycle pathways are interconnected: Implications for cancer therapy. Drug Resist Updat 10: 13-29, 2007.

3. Brooks SA, Lomax-Browne HJ, Carter TM, Kinch CE and Hall DM: Molecular interactions in cancer cell metastasis. Acta Histochem 112: 3-25, 2010

4. Valastyan S and Weinberg RA: Tumor metastasis: Molecular insights and evolving paradigms. Cell 147: 275-292, 2011.

5. Petrylak DP: The current role of chemotherapy in metastatic hormone-refractory prostate cancer. Urology 65 (Suppl): 3-7, discussion 7-8, 2005.

6. Evans T: Chemotherapy in advanced non-small cell lung cancer. Semin Respir Crit Care Med 26: 304-313, 2005.

7. Mondal S, Bandyopadhyay S, Ghosh MK, Mukhopadhyay S, Roy S and Mandal C: Natural products: Promising resources for cancer drug discovery. Anticancer Agents Med Chem 12: 49-75, 2012.

8. Corson TW and Crews CM: Molecular understanding and modern application of traditional medicines: Triumphs and trials. Cell 130: 769-774, 2007.

9. Kiyohara H, Matsumoto T and Yamada H: Combination effects of herbs in a multi-herbal formula: Expression of Juzen-taiho-to's immuno-modulatory activity on the intestinal immune system. Evid Based Complement Alternat Med 1: 83-91, 2004.

10. Kim DS, Kim SH, Kim BK, Yang MC and Ma JY: Antiasthmatic Effects of herbal complex MA and its fermented product MA128. Evid Based Complement Alternat Med 2012: 769508, 2012.

11. Chung TH, Kang TJ, Cho WK, Im GY, Lee GS, Yang MC, Cho CW and Ma JY: Effectiveness of the novel herbal medicine, KIOM-MA, and its bioconversionproduct, KIOM-MA128, on the treatment of atopic dermatitis. Evid Based Complement Alternat Med 2012: 762918, 2012.

12. Kim A and Ma JY: Anti-melanogenic activity of the novel herbal medicine, MA128, through inhibition of tyrosinase activity mediated by the p38 mitogen-activated protein kinases and protein kinase signaling pathway in B16F10 cells. Pharmacogn Mag 10 (Suppl 3): S463-S471, 2014.

13. Kim A, Im M, Yim NH, Kim T and Ma JY: A novel herbal medicine, $\mathrm{KIOM}-\mathrm{C}$, induces autophagic and apoptotic cell death mediated by activation of JNK and reactive oxygen species in HT1080 human fibrosarcoma cells. PLoS One 9: e98703, 2014.

14. Kim A, Im M, Yim NH, Jung YP and Ma JY: Aqueous extract of Bambusae Caulis in Taeniam inhibits PMA-induced tumor cell invasion and pulmonary metastasis: Suppression of NF- $\kappa B$ activation through ROS signaling. PLoS One 8: e78061, 2013.
15. Kim A, Yim NH, Im M, Jung YP, Kim T and Ma JY: Suppression of the invasive potential of highly malignant tumor cells by KIOM-C, a novel herbal medicine, via inhibition of $N F-\kappa B$ activation and MMP-9 expression. Oncol Rep 31: 287-297, 2014.

16. Kim A, Im M, Yim NH and Ma JY: Reduction of metastatic and angiogenic potency of malignant cancer by Eupatorium fortunei via suppression of MMP-9 activity and VEGF production. Sci Rep 4: 6994, 2014.

17. Jin Z and El-Deiry WS: Overview of cell death signaling pathways. Cancer Biol Ther 4: 139-163, 2005.

18. Ouyang L, Shi Z, Zhao S, Wang FT, Zhou TT, Liu B and Bao JK: Programmed cell death pathways in cancer: A review of apoptosis, autophagy and programmed necrosis. Cell Prolif 45: 487-498, 2012.

19. Reddy KB, Nabha SM and Atanaskova N: Role of MAP kinase in tumor progression and invasion. Cancer Metastasis Rev 22: 395-403, 2003.

20. Roomi MW, Monterrey JC, Kalinovsky T, Rath $\mathrm{M}$ and Niedzwiecki A: Patterns of MMP-2 and MMP-9 expression in human cancer cell lines. Oncol Rep 21: 1323-1333, 2009.

21. Choi JH, Han EH, Hwang YP, Choi JM, Choi CY, Chung YC, Seo JK and Jeong HG: Suppression of PMA-induced tumor cell invasion and metastasis by aqueous extract isolated from Prunella vulgaris via the inhibition of NF- $\kappa \mathrm{B}$-dependent MMP-9 expression. Food Chem Toxicol 48: 564-571, 2010.

22. Hwang YP, Yun HJ, Kim HG, Han EH, Lee GW and Jeong HG: Suppression of PMA-induced tumor cell invasion by dihydroartemisinin via inhibition of PKC $\alpha /$ Raf/MAPKs and NF- $\kappa \mathrm{B} / \mathrm{AP}-1-$ dependent mechanisms. Biochem Pharmacol 79: 1714-1726, 2010.

23. Kim A, Kim MJ, Yang Y, Kim JW, Yeom YI and Lim JS: Suppression of NF- $\kappa$ B activity by NDRG2 expression attenuates the invasive potential of highly malignant tumor cells. Carcinogenesis 30: 927-936, 2009.

24. Yeh CB,Hsieh MJ, Hsieh YH, Chien MH, Chiou HL and Yang SF: Antimetastatic effects of norcantharidin on hepatocellular carcinoma by transcriptional inhibition of MMP-9 through modulation of NF-kB activity. PLoS One 7: e31055, 2012.

25. Risau W: Mechanisms of angiogenesis. Nature 386: 671-674, 1997.

26. Jang YJ, Kim DS, Jeon OH and Kim DS: Saxatilin suppresses tumor-induced angiogenesis by regulating VEGF expression in NCI-H460 human lung cancer cells. J Biochem Mol Biol 40: 439-443, 2007.

27. Grant DS, Yenisey C, Rose RW, Tootell M, Santra M and Iozzo RV: Decorin suppresses tumor cell-mediated angiogenesis. Oncogene 21: 4765-4777, 2002.

28. Hirota K and Semenza GL: Regulation of angiogenesis by hypoxia-inducible factor 1. Crit Rev Oncol Hematol 59: 15-26, 2006.

29. Woo SM, Choi YK, Cho SG, Park S and Ko SG: A new herbal formula, KSG-002, suppresses breast cancer growth and metastasis by targeting NF- $\kappa \mathrm{B}$-dependent TNF $\alpha$ production in macrophages. Evid Based Complement Alternat Med 2013: $728258,2013$.

30. Lee HJ, Lee EO, Rhee YH, Ahn KS, Li GX, Jiang C, Lü J and Kim SH: An oriental herbal cocktail, ka-mi-kae-kyuk-tang, exerts anti-cancer activities by targeting angiogenesis, apoptosis and metastasis. Carcinogenesis 27: 2455-2463, 2006.

31. Buchanan DR, White JD, O'Mara AM, Kelaghan JW, Smith WB and Minasian LM: Research-design issues in cancer-symptom-management trials using complementary and alternative medicine: Lessons from the National Cancer Institute Community Clinical Oncology Program experience. J Clin Oncol 23: 6682-6689, 2005

32. Kim SC, Byun SH, Yang CH, Kim CY, Kim JW and Kim SG: Cytoprotective effects of Glycyrrhizae radix extract and its active component liquiritigenin against cadmium-induced toxicity (effects on bad translocation and cytochrome c-mediated PARP cleavage). Toxicology 197: 239-251, 2004.

33. Xiao ZM, Wang AM, Wang XY and Shen SR: Effects of ethanol extract of Radix Sophorae Flavescentis on activity of colon cancer HT29 cells. Afr J Tradit Complement Altern Med 10: 352-355, 2013.

34. Yang S, Ma J, Xiao J, Lv X, Li X, Yang H, Liu Y, Feng S and Zhang Y: Arctigenin anti-tumor activity in bladder cancer T24 cell line through induction of cell-cycle arrest and apoptosis. Anat Rec (Hoboken) 295: 1260-1266, 2012. 
35. Shin JA, Shim JH, Jeon JG, Choi KH, Choi ES, Cho NP and Cho SD: Apoptotic effect of Polygonum cuspidatum in oral cancer cells through the regulation of specificity protein 1 . Oral Dis 17: 162-170, 2011.

36. Jung MH, Lee SH, Ahn EM and Lee YM: Decursin and decursinol angelate inhibit VEGF-induced angiogenesis via suppression of the VEGFR-2-signaling pathway. Carcinogenesis 30: 655-661, 2009.

37. Kim WJ, Lee SJ, Choi YD and Moon SK: Decursin inhibits growth of human bladder and colon cancer cells via apoptosis, G1-phase cell cycle arrest and extracellular signal-regulated kinase activation. Int J Mol Med 25: 635-641, 2010.

38. Son SH, Park KK, Park SK, Kim YC, Kim YS, Lee SK and Chung WY: Decursin and decursinol from Angelica gigas inhibit the lung metastasis of murine colon carcinoma. Phytother Res 25: 959-964, 2011.

39. Zhang Y, Zhang H, Yu P, Liu Q, Liu K, Duan H, Luan G, Yagasaki $\mathrm{K}$ and Zhang G: Effects of matrine against the growth of human lung cancer and hepatoma cells as well as lung cancer cell migration. Cytotechnology 59: 191-200, 2009.

40. Ma L, Wen S, Zhan Y, He Y, Liu X and Jiang J: Anticancer effects of the Chinese medicine matrine on murine hepatocellular carcinoma cells. Planta Med 74: 245-251, 2008.
41. Thirugnanam S, Xu L, Ramaswamy $\mathrm{K}$ and Gnanasekar M: Glycyrrhizin induces apoptosis in prostate cancer cell lines DU-145 and LNCaP. Oncol Rep 20: 1387-1392, 2008.

42. Liu XY, Fang H, Yang ZG, Wang XY, Ruan LM, Fang DR, Ding YG, Wang YN, Zhang Y, Jiang XL, et al: Matrine inhibits invasiveness and metastasis of human malignant melanoma cell line A375 in vitro. Int J Dermatol 47: 448-456, 2008.

43. Wang Y, Dong H, Zhu M, Ou Y, Zhang J, Luo H, Luo R, Wu J, Mao M, Liu X, et al: Icariin exterts negative effects on human gastric cancer cell invasion and migration by vasodilator-stimulated phosphoprotein via Rac1 pathway. Eur J Pharmacol 635: 40-48, 2010.

44. Li S, Dong P, Wang J, Zhang J, Gu J, Wu X, Wu W, Fei X, Zhang Z, Wang Y, et al: Icariin, a natural flavonol glycoside, induces apoptosis in human hepatoma SMMC-7721 cells via a ROS/JNK-dependent mitochondrial pathway. Cancer Lett 298: 222-230, 2010.

45. Gondi CS, Lakka SS, Dinh DH, Olivero WC, Gujrati $M$ and Rao JS: Downregulation of uPA, uPAR and MMP-9 using small, interfering, hairpin RNA (siRNA) inhibits glioma cell invasion, angiogenesis and tumor growth. Neuron Glia Biol 1: 165-176, 2004 . 